\title{
Correction to: Managing Talent
}

\section{Billy Adamsen and Stephen Swailes}

https://doi.org/10.1007/978-3-319-95201-7

This book was inadvertently published without the Acknowledgements. The same have been added.

The updated online version of this book can be found at https://doi.org/10.1007/978-3-319-95201-7

\section{B. Adamsen $(\bowtie)$}

Talent Lab, Zealand Institute of Business and Technology, Slagelse, Denmark e-mail: bian@easj.dk

S. Swailes

Huddersfield Business School, University of Huddersfield, Huddersfield, UK e-mail: s.swailes@hud.ac.uk 